\title{
A comparative study between lateral internal anal sphincterotomy and botulinum toxin injection in the treatment of chronic anal fissure
}

\begin{tabular}{cc}
\hline Abdulqadir M. Zngana ${ }^{1}$ & Bawan Hiwa $^{2 *}$ \\
\hline Abstract $^{2}$ &
\end{tabular}

Background and objective: The gold standard for the treatment of chronic anal fissure is lateral internal sphincterotomy. Botulinum toxin injection provides temporary alleviation of sphincter spasm and allows the fissure to heal. This study aimed to compare the outcomes of lateral internal sphincterotomy and botulinum toxin injection treatments in patients with uncomplicated chronic anal fissure.

Methods: A prospective comparative study was carried out at the surgical unit of Erbil teaching hospital, Erbil, Kurdistan Region of Iraq, from January 2017 to February 2018. Fifty-five patients were enrolled in this study. Five patients were excluded, and the remaining 50 patients were equally divided into two groups. Group A was managed with lateral internal sphincterotomy and group B with botulinum toxin. Postoperative pain relief, bleeding, fissure healing, incontinence, and relapse after six weeks and three months of follow-up were compared.

Results: One month after treatment, $12 \%$ of the lateral internal sphincterotomy group had bleeding, while none of the botulinum toxin group $(P=0.234)$. Two patients $(8 \%)$ of the lateral internal sphincterotomy group had pain while one (4\%) of the botulinum toxin group $(P>0.999)$. Three months after treatment, $4 \%$ of the lateral internal sphincterotomy group had bleeding, while none of the botulinum toxin group $(P>0.999)$. None of the lateral internal sphincterotomy group had pain while one (4\%) of the botulinum toxin group $(P>0.999)$. Regarding healing, $96 \%$ of the lateral internal sphincterotomy group healed, while $92 \%$ in the botulinum toxin group $(P>0.999)$.

Conclusion: The outcome of lateral internal sphincterotomy and botulinum toxin were nearly the same, but lateral internal sphincterotomy required hospitalization, period off work, and risk of anesthesia. These risks were absent in botulinum toxin injection.

Keywords: Chronic anal fissure; Lateral internal sphincterotomy; Botulinum toxin; Complications.

\section{Introduction}

An anal fissure is a linear ulcer in the anoderm, distal to the dentate line. ${ }^{1-3}$ The pathophysiology of anal fissure is thought to be related to trauma from either the passage of hard stool or prolonged diarrhea. A tear in the anoderm causes spasm of the internal anal sphincter, which results in pain, increased tearing, and decreased blood supply to the anoderm. This cycle contributes to the development of a poorly healing wound that becomes a chronic fissure. ${ }^{4}$ A chronic fissure is defined as a fissure that has not healed and symptoms present for greater than 2-3 months of treatment. ${ }^{1-3,5}$ The clinical hallmarks are post-defecation pain and/or bleeding. The sphincter spasm seems to cause relative local ischemia that precludes the healing of the fissure. ${ }^{1,6}$ The vast majority of anal fissures occur in the posterior midline (where the blood supply is relatively poor), but other locations are also found. Around $10-15 \%$ occur in the anterior midline, while less than $1 \%$ of fissures occur off the midline. ${ }^{3-5}$ Fissures in

${ }^{1}$ Department of Surgery, College of Medicine, Hawler Medical University, Erbil, I raq.

2 Department of General Surgery, Erbil Teaching Hospital, Erbil, I raq.

* Correspondence: bawan_hewa@yahoo.com 
lateral positions should raise suspicion for an underlying disease such as Crohn's disease, venereal infection, trauma, tuberculosis, human immunodeficiency virus, dermatologic conditions, chemotherapy, and local or systemic malignancy. ${ }^{2-4}$ Contemporary management for chronic anal fissure focuses on reducing the spasm of the internal anal sphincter and relief of symptoms. Surgical sphincterotomy, which provides symptomatic relief and healing, is highly effective but can be associated with permanent complications. ${ }^{1,4}$ Auxiliary medical and noninvasive approaches have been proposed to treat this condition without any risk of permanent internal sphincter injury. One of these methods is chemical denervation with botulinum toxin, ${ }^{5,6}$ which may decrease anal pressure for three months or more, permitting the fissure to restore to the healthy tissue and avoiding the need for surgery. Botulinum toxin and lateral internal sphincterotomy are the main therapeutic options for refractory fissures. Botulinum toxin causes a temporary sphincter paresis for approximately three months, allowing fissure healing. The release of acetylcholine at the presynaptic nerve endings with neuromuscular transmission blockade causes chemical denervation of the sphincter muscles. ${ }^{6}$ Botulinum toxin is a safe and effective treatment, well tolerated, minimally invasive, and administered on an outpatient basis. Currently, there is no consensus on dosage, the precise site of administration, or the number of injections to perform, ${ }^{6,7}$ although botulinum toxin has been in use since the $1994 .^{8}$ This study aimed to find out the effect of the outcomes of the botulinum toxin injection treatments for postoperative pain relief, bleeding, fissure healing, incontinence, and fissure relapse in patients with an uncomplicated chronic anal fissure and compared with lateral internal sphincterotomy

\section{Methods}

A prospective comparative study was carried out in the surgical unit of Erbil teaching hospital, located in Erbil, Iraq, from January 2017 to February 2018. The inclusion criteria were history of symptoms of more than three months (bleeding per rectum, pain during defecation and itching, etc.), induration of edges of fissure with no edema/inflammation, sentinel pile, hypertrophied anal papilla, and a chronic anal fissure lasting more than six weeks. The exclusion criteria were pregnancy, cardiovascular disease or heart failure, antihypertensive medications, recurrent anal fissure after previous sphincterotomy, prior history of anal surgery, and other benign anorectal diseases with inflammatory bowel diseases. Out of 55 consecutive patients enrolled in this study, five patients were excluded from the study because of the loss of follow-up. The remaining 50 patients with uncomplicated chronic anal fissures with failure of conservative treatment were equally divided into two groups. Group A was managed with lateral internal sphincterotomy and group B with botulinum toxin. Patients were divided randomly into two groups using the Microsoft Excel computer program. The diagnosis of the anal fissure was based on the following clinical criteria: evidence of circumscribed ulcer, with a large sentinel tag of skin, indurations at the edges, and exposure of the horizontal fibers of the internal anal sphincter and symptoms lasting for more than six weeks. After giving informed consent, eligible patients underwent treatment randomly with either lateral internal anal sphincterotomy or botulinum toxin A. Botulinum toxin A (Botox, Allergan, Irvin, UK) was diluted in $0.5 \mathrm{ml}$ saline solution. Each patient received Botulinum toxin (for a total of 20 unit) administered as divided doses through the internal anal sphincter at 3, 9 and 12 o'clock and injection for an equal volume on each side of the fissure, by a so-called insulin syringe with a short, thin needle $(10 \mathrm{~mm}, 26$ 
needle). No sedation or local anesthesia was used during the procedure. After injection, conservative measures, such as sitting baths and/or anal tampons for the period of healing (at least for the first weeks), were recommended. Surgeons evaluating the results were blinded to the procedure. Lateral internal sphincterotomy was performed under general or spinal anesthesia in the lithotomy position by a technique through a circumferential incision placed laterally to the skin outside the anal verge. The anoderm and intersphincteric groove were dissected, and then the sphincter was divided under direct vision. The wound was either left open or was closed with interrupted sutures. The result of the study was nearly complete healing after treatment at the end of 3 months of follow up. The treatment was considered successful if the fissure healed. Persistence of the fissure in the absence of symptoms was considered as symptomatic improvement. Statistical analysis was conducted through the 'openepi.com' statistical website and the epi info 7 computer program, a free software issued by the Centers for Disease Control and Prevention (CDC). The Chi square test of association was used to compare the proportions of the two study groups. When the expected count of more than $20 \%$ of the cells of the table was less than 5, Fisher's exact test was used instead of the Chi square test. A $P$ value of less than 0.05 was considered statistically significant.

\section{Results}

Fifty patients participated in the study, 25 patients underwent lateral internal sphincterotomy, and 25 patients got botulinum toxin. Most patients reported severe pain after defecation, and each had a posterior anal fissure with a large sentinel tag of skin and some with exposed internal anal sphincter fibers. Presenting complaints in these patients were painful defecation and constipation in 46 (92\%) patients, bleeding per rectum in $50(100 \%)$ patients, discharge per rectum in $25(50 \%)$ patients, sentinel pile in $30(60 \%)$ patients, and pruritus in $13(26 \%)$ patients. In this study, 46 (92\%) patients had posterior midline fissure, and 4 (8\%) had anterior midline fissure. The mean age $( \pm S D)$ of the patients was $39.52 \pm 4.55$ years, ranging from 18-65 years. Table 1 shows that the largest proportion of the whole sample $(26 \%)$ aged $38-47$ years, and $24 \%$ aged 48-57 years, but there was no significant difference between the two groups regarding the age distribution $(P=0.957)$. The majority $(72 \%)$ of the sample were males $(80 \%$ in the lateral internal sphincterotomy group and 64\% in the botulinum toxin group), but the difference was not significant between the two groups $(P=0.208)$. The male:female ratio was $2.57: 1$.

Table 1: Baseline characteristics of 50 patients with chronic posterior anal fissure.

\begin{tabular}{lccccccc}
\hline Variable & \multicolumn{2}{c}{$\begin{array}{c}\text { Group A } \\
\text { (lateral internal sphincterotomy) } \\
\text { No. }\end{array}$} & $\begin{array}{c}\text { Group B } \\
\text { (\%) }\end{array}$ & No. & (\%) & No. & (\%) \\
\hline Age (years) & & & & & & & Total \\
$18-27$ & 3 & $(12.0)$ & 4 & $(16.0)$ & 7 & $(14.0)$ \\
$28-37$ & 6 & $(24.0)$ & 5 & $(20.0)$ & 11 & $(22.0)$ & \\
$38-47$ & 7 & $(28.0)$ & 6 & $(24.0)$ & 13 & $(26.0)$ & $0.957 \dagger$ \\
$48-57$ & 5 & $(20.0)$ & 7 & $(28.0)$ & 12 & $(24.0)$ & \\
$58-65$ & 4 & $(16.0)$ & 3 & $(12.0)$ & 7 & $(14.0)$ & \\
Gender & & & & & & & \\
Male & 20 & $(80.0)$ & 16 & $(64.0)$ & 36 & $(72.0)$ & $0.208^{\star}$ \\
Female & 5 & $(20.0)$ & 9 & $(36.0)$ & 14 & $(28.0)$ & \\
Total & 25 & $(100.0)$ & 25 & $(100.0)$ & 50 & $(100.0)$ & \\
\hline
\end{tabular}

†By the Fisher's exact test. *By the Chi square test. 
It is evident in Table 2 that, one month after treatment, $12 \%$ of the lateral internal sphincterotomy group had bleeding, while none of the botulinum toxin group had bleeding $(P=0.234)$. Two patients $(8 \%)$ of the lateral internal sphincterotomy group had pain compared with one patient $(4 \%)$ of the botulinum toxin group $(P>0.999)$. Three months after treatment, Table 3 shows that one patient $(4 \%)$ of the lateral internal sphincterotomy group had bleeding, while none of the patients of the botulinum toxin group had bleeding $(P>0.999)$. None of the patients of the lateral internal sphincterotomy group had pain, while one patient (4\%) of the botulinum toxin group had pain $(P>0.999)$. Regarding healing, $96 \%$ of the wounds of patients of the lateral internal sphincterotomy group healed, compared with $92 \%$ of patients of the botulinum toxin group $(P>0.999)$.

Table 2: Symptoms in the two groups one month after treatment.

\begin{tabular}{|c|c|c|c|c|c|c|c|}
\hline \multirow[t]{2}{*}{ Variable } & \multicolumn{2}{|c|}{$\begin{array}{l}\text { Group A (lateral internal } \\
\text { sphincterotomy) }\end{array}$} & \multicolumn{2}{|c|}{$\begin{array}{c}\text { Group B (botulinum } \\
\text { toxin) }\end{array}$} & \multicolumn{2}{|c|}{ Total } & \multirow[t]{2}{*}{$P$ value* } \\
\hline & No. & (\%) & No. & (\%) & No. & (\%) & \\
\hline \multicolumn{8}{|l|}{ Bleeding } \\
\hline No & 22 & $(88.0)$ & 25 & (100.0) & 47 & $(94.0)$ & 0.234 \\
\hline Yes & 3 & $(12.0)$ & 0 & $(0.0)$ & 3 & (6.0) & \\
\hline \multicolumn{8}{|l|}{ Pain } \\
\hline No & 23 & $(92.0)$ & 24 & $(96.0)$ & 47 & $(94.0)$ & $>0.999$ \\
\hline Yes & 2 & $(8.0)$ & 1 & $(4.0)$ & 3 & $(6.0)$ & \\
\hline Total & 25 & $(100.0)$ & 25 & $(100.0)$ & 50 & $(100.0)$ & \\
\hline
\end{tabular}

*By Fisher's exact test

Table 3: Symptoms in the two groups 3 months after treatment.

\begin{tabular}{lccccccc}
\hline Variable & $\begin{array}{c}\text { Group A (lateral internal } \\
\text { sphincterotomy) }\end{array}$ & \multicolumn{2}{c}{$\begin{array}{c}\text { Group B (botulinum } \\
\text { toxin) }\end{array}$} & \multicolumn{2}{c}{ Total } & P value* $^{*}$ \\
& No. & $(\%)$ & No. & $(\%)$ & No. & (\%) & \\
\hline Bleeding & & & & & & & \\
No & 24 & $(96.0)$ & 25 & $(100.0)$ & 49 & $\mathbf{( 9 8 . 0 )}$ & $>0.999$ \\
Yes & 1 & $(4.0)$ & 0 & $(0.0)$ & 1 & $(2.0)$ & \\
Pain & & & & & & & \\
No & 25 & $(100.0)$ & 24 & $(96.0)$ & 49 & $(98.0)$ & $>0.999$ \\
Yes & 0 & $(0.0)$ & 1 & $(4.0)$ & 1 & $(2.0)$ & \\
Healing & & & & & & & \\
No & 1 & $(4.0)$ & 2 & $(8.0)$ & 3 & $(6.0)$ & $>0.999$ \\
Yes & 24 & $(96.0)$ & 23 & $(92.0)$ & 47 & $(94.0)$ & \\
Total & $\mathbf{2 5}$ & $(\mathbf{1 0 0 . 0 )}$ & $\mathbf{2 5}$ & $\mathbf{( 1 0 0 . 0 )}$ & $\mathbf{5 0}$ & $\mathbf{( 1 0 0 . 0 )}$ & \\
\hline
\end{tabular}

†By Fisher's exact test 
It is evident in Table 4 that $32 \%$ and $36 \%$ of the wound of patients of the botulinum toxin group healed at two weeks and four weeks, respectively, compared with $16 \%$ and $16 \%$ of patients of the lateral internal sphincterotomy group, respectively $(P=0.043)$. The table shows that $64 \%$ of the wounds of the lateral internal sphincterotomy group healed after six weeks.So, in general, the time of healing is less in the botulinum toxin group. Results showed that the recurrence rate after six months was $20 \%$ (5 patients) in the toxin group and $8 \%$ (2 patients) in the operation group ( $P=0.417$ by Fisher's exact test).

\section{Discussion}

Over the years, various hypotheses have been presented regarding the development of anal fissures. From anal trauma to internal sphincter hypertonia and resultant local ischemia resulting in non-healing have been postulated as the contributing factors. ${ }^{1,6}$ Many treatment options are available for anal fissures, including pharmacological and surgical interventions. Whatever the mode of treatment, the principal aim is to decrease the tone of the internal anal sphincter that increases local blood flow, subsequently leading to healing. ${ }^{9-11 .}$ Botulinum toxin exerts its effects on the peripheral nerve ending by blockade of sympathetic (noradrenaline mediated) neural output. This is probably a postganglionic action involving a reduction in noradrenaline release at the neuromuscular junction, resulting in flaccid paralysis and causes a transitional period of powerlessness to the internal anal sphincter muscle. ${ }^{12}$ Botulinum toxin inhibits contraction of gastrointestinal smooth muscle. Therefore, the toxin is effective in treating anal fissure when injected into the internal anal sphincter, avoiding permanent complications. Chemical denervation with botulinum toxin has been proposed as a noninvasive and less expensive than surgical intervention alternative treatment for chronic anal fissure. ${ }^{13,14}$ Surgery for treating this condition required hospitalization and period off work. There was also the risk of complications of general or spinal anesthesia. ${ }^{14}$ Botulinum toxin can be used in the outpatient department to treat chronic fissures. The results showed that lateral internal sphincterotomy and botulinum toxin injection treatment modalities had similar effects (no significant difference) on fissure healing rates. So, we can suggest that lateral internal sphincterotomy and botulinum toxin injection treatments are equally effective in treating patients with chronic anal fissure. In our study, botulinum toxin was faster in fissure healing than lateral sphincterotomy. Previous studies have demonstrated a healing rate ranging from 75 to more than 90 percent, ${ }^{8,9,15}$ after a single injection of 15 or $20 \mathrm{IU}$ of toxin in the internal anal

Table 4: Time of healing of fissures in each of the study groups.

\begin{tabular}{lccccc}
\hline Healing time & $\begin{array}{c}\text { Group A (lateral internal } \\
\text { sphincterotomy) }\end{array}$ & $\begin{array}{c}\text { Group B (botulinum } \\
\text { toxin) }\end{array}$ & $P$ value* \\
& No. & $(\%)$ & No. & (\%) & \\
\hline After 2 weeks & 4 & $(16.0)$ & 8 & $(32.0)$ & \\
After 4 weeks & 4 & $(16.0)$ & 9 & $(36.0)$ & 0.043 \\
After 6 weeks & 16 & $(64.0)$ & 6 & $(24.0)$ & \\
No healing after 3 months & 1 & $(4.0)$ & 2 & $(8.0)$ & \\
Total & 25 & $(100.0)$ & 25 & $(100.0)$ & \\
\hline
\end{tabular}

*By the Chi square test. 
sphincter ${ }^{8,12}$ which is more or less similar to our results. The follow-up of chronic anal fissure after healing by this new nonsurgical intervention is quite different. With 6 to 24 months of follow up, the recurrence rates varied from 0 to 8 percent. ${ }^{9,16}$ Arroya and co-workers showed a recurrence rate of $55 \%$ in the first year of the follow up after treatment of chronic anal fissure with botulinum toxin.17 Minguez reported a $41.5 \%$ incidence of recurrence rate after 42 months of the follow up. ${ }^{16}$ However, in many other studies, the healing rate by botulinum toxin ranged between $41-90.7 \%$ at three months, with recurrence rates of $20.6-54 \%$ at six months. ${ }^{1,7,18-23}$ Their results, more or less, coincide with our results. In our study, the healing rate by botulinum toxin was $92 \%$ at three months, and the recurrence rate after six months was $20 \%$ in the toxin group and $8 \%$ in the operation group. Lateral internal sphincterotomy is a better option for those patients who had non-successes of the other way of dealing treatments with a good result of healing rate and a lower rate of recurrence rate but associated with more complications. ${ }^{24}$ Though the success rate in the toxin group did not differ significantly from the surgical group, it was performed without hospital admission, anesthesia, incision, and complicated postoperative care. When we offer this type of therapy to patients, all were eager to receive it despite being new in our locality. Because spasm of the anal sphincter has been noted in association with the anal fissure, for many years, the aim of treatment was to reduce hypertonia of the sphincter. We have been unable to perform anal manometry because it is not available in our department. However, in the clinical evaluation, it seems that botulinum toxin is an effective alternative modality for the treatment of chronic anal fissure. We recommend an injection of botulinum toxin as the first step in the treatment of chronic anal fissure because of the $92 \%$ chance of cure with an easily performed treatment.

\section{Conclusion}

Botulinum toxin injection had nearly the same effects as lateral internal sphincterotomy for postoperative pain relief, bleeding, fissure healing, incontinence, and fissure relapse in patients with uncomplicated chronic anal fissure. Moreover, botulinum toxin injection does not require hospitalization, general or spinal anesthesia, and period off work that are needed in the lateral internal sphincterotomy management. Larger scale, randomized controlled trials with long term follow up are needed before making firm conclusions about the advantages of this treatment modality over the conventional methods.

\section{Competing interests}

The authors declare no competing interests.

\section{References}

1. Whatley JZ, Tang SJ, Glover PH, Davis ED, Jex KT, Wu R, et al. Management of complicated chronic anal fissures with high-dose circumferential chemodenervation (HDCC) of the internal anal sphincter. Int J Surg 2015; 24:24-6.

2. Nelson RL, Thomas $\mathrm{K}$, Morgan J, Jones $A$. Non surgical therapy for anal fissure. Cochrane Database Syst Rev 2012; 2012(2):CD003431.

3. Wald A, Bharucha AE, Cosman BC, Whitehead WE. ACG clinical guideline: Management of benign anorectal disorders. Am J Gastroenterol 2014; 109(8):1141-57.

4. Kwaan MR, Stewart DB, Dunn KB. Colon, Rectum, and Anus. Text book of Schwart's principle of surgery. $11^{\text {th }}$ ed. United States of America: McGraw-Hill Education; 2019. P.1313.

5. Aarons CB, Sentovich SM. Anorectum. Text book of Current diagnosis and treatment surgery. $14^{\text {th }}$ ed. United States of America:McGraw-Hill Education; 2015. P. 746.

6. Halahakoon VC, Pitt JP. Anal advancement flap and botulinum toxin A (BT) for chronic anal fissure (CAF). Int $\mathrm{J}$ Colorectal Dis 2014; 29(9):1175-7.

7. Glover PH, Tang SJ, Whatley JZ, Davis ED, Jex KT, Wu R, et al. High-dose circumferential chemodenervation of the internal anal sphincter: A new treatment modality for uncomplicated chronic anal fissure: A retrospective cohort study (with video). Int J Surg 2015; 23:1-4.

8. Bhardwaj R, Drye E, Vaizey C. Novel delivery of botulinum toxin for the treatment of anal fissures. Colorectal Dis 2006; 8(4):360-4. 
9. Piccinni G, Poli E, Angrisano A, Sciusco A, Testini M. Botox for chronic anal fissure: is it useful? A clinical experience with mid-term follow-up. Acta Biomed 2009; 80(3):238-42.

10. Dhawan S, Chopra S. Nonsurgical Approaches for the Treatment of Anal Fissures: CME. Am J Gastroenterol 2007; 102(6):1312-21.

11. Iswariah H, Stephens J, Rieger N, Rodda D, Hewett P. Randomized prospective controlled trial of lateral internal sphincterotomy versus injection of botulinum toxin for the treatment of idiopathic fissure in ano. ANZ journal of surgery 2005; 75(7):553-5.

12. Jones OM, Brading AF, Mortensen NM. Mechanism of action of botulinum toxin on the internal anal sphincter. Br J Surg 2004; 91(2):224 $-8$.

13. Daniel F, Siproudhis L, Atienza P. Botulinum toxin and chronic anal fissure. Gastroen Clin Biol 2006; 30(5):687-95.

14. Valizadeh N, Jalaly NY, Hassanzadeh M, Kamani F, Dadvar Z, Azizi S, et al. Botulinum toxin injection versus lateral internal sphincterotomy for the treatment of chronic anal fissure: randomized prospective controlled trial. Langenbeck's Arch Surg 2012; 397(7):1093-8.

15. Witte ME, Klaase JM. Botulinum toxin A injection in ISDN ointment-resistant chronic anal fissures. Dig Surg 2007; 24(3):197-201.

16. Minguez $M$, Herreros $B$, Sanchiz $V$, Mora $F$, Benages $A$, EspiA, et al. Long-term follow-up (42 months) of chronic anal fissure after healing with botulinum toxin. Gastroenterology 2002; 123(1):112-7.

17. Arroyo A, Pérez $F$, Serrano $P$, Candela $F$, Lacueva J, Calpena R. Surgical versus chemical (botulinum toxin) sphincterotomy for chronic anal fissure: long-term results of a prospective randomized clinical and manometric study. Am J Surg 2005; 189(4):429-34.

18. Yiannakopoulou E. Botulinum toxin and anal fissure: efficacy and safety systematic review. Int J Colorectal Dis 2012; 27(1):1-9.

19. Sajid MS, Hunte S, Hippolyte S, Kiri VA, Maringe C, Baig MK. Comparison of surgical vs. chemical sphincterotomy using botulinum toxin for the treatment of chronic anal fissure: a meta-analysis. Colorectal Dis 2008; 10(6):547-52.

20. Sinha R, Kaiser AM. Efficacy of management algorithm for reducing need for sphincterotomy in chronic anal fissures. Colorectal Dis 2012; 14(6):760-4.

21. Witte ME, Klaase JM. Botulinum toxin A injection in ISDN ointment-resistant chronic anal fissures. Dig Surg 2007; 24(3):197-201.

22. Nasr M, Ezzat $H$, Elsebae M. Botulinum toxin injection versus lateral internal sphincterotomy in the treatment of chronic anal fissure: a randomized controlled trial. World J Surg 2010; 34(11):2730-4.
23. Berkel AE, Rosman C, Koop R, van Duijvendijk $\mathrm{P}$, van der Palen $\mathrm{J}$, Klaase JM. Isosorbide dinitrate ointment vs. botulinum toxin A (D ysport ${ }^{\circledR}$ ) as the primary treatment for chronic anal fissure: a randomized multicentre study. Colorectal Dis 2014; 16(10):O360-6.

24. Chen HL, Woo XB, Wang HS, Lin $Y J$, Luo HX, Chen $\mathrm{YH}$, et al. Botulinum toxin injection versus lateral internal sphincterotomy for chronic anal fissure: a meta-analysis of randomized control trials. Tech Coloproctol 2014; 18(8):693-8. 